\title{
Review
}

\section{Septohippocampal Acetylcholine: Involved in but not Necessary for Learning and Memory?}

\author{
Marise B. Parent ${ }^{1,3}$ and Mark G. Baxter ${ }^{2,3}$ \\ ${ }^{1}$ Department of Psychology and Center for Behavioral Neuroscience, Georgia State University, Atlanta Georgia 30303, USA \\ ${ }^{2}$ Department of Experimental Psychology, Oxford University, Oxford OX1 3UD, Oxford, UK
}

\begin{abstract}
The neurotransmitter acetylcholine $(\mathrm{ACh})$ has been accorded an important role in supporting learning and memory processes in the hippocampus. Cholinergic activity in the hippocampus is correlated with memory, and restoration of $\mathrm{ACh}$ in the hippocampus after disruption of the septohippocampal pathway is sufficient to rescue memory. However, selective ablation of cholinergic septohippocampal projections is largely without effect on hippocampal-dependent learning and memory processes. We consider the evidence underlying each of these statements, and the contradictions they pose for understanding the functional role of hippocampal $\mathrm{ACh}$ in memory. We suggest that although hippocampal $\mathrm{ACh}$ is involved in memory in the intact brain, it is not necessary for many aspects of hippocampal memory function.
\end{abstract}

The goal of this review is to consider the role of septohippocampal acetylcholine (ACh) in learning and memory processes. The evidence in this regard falls broadly into two different classes. On the one hand, considerable data implicate septohippocampal ACh in memory function. This system is engaged during memory processing, indexed by ACh release or by modification of cholinergic markers, and manipulations that affect memory produce parallel changes in hippocampal cholinergic activity. Furthermore, agents that increase hippocampal cholinergic function are sufficient to reverse memory impairments caused by disruption of the septohippocampal system. However, data from studies of selective lesions of septohippocampal cholinergic neurons with the immunotoxin 192 IgG-saporin call into question the essential role of this system in learning and memory, because these studies generally failed to find severe impairments in memory function. Our goal in this article is to review the data underlying each of these lines of evidence, and to attempt to reconcile these apparently disparate observations.

The discrepancy between these lines of evidence might imply that septohippocampal ACh is involved in memory processing, but is not necessary for it to occur. This viewpoint would allow for correlated changes in ACh release and memory, and for the ability of cholinergic agents to reverse memory impairments caused by disruption of septohippocampal function. However, it also would permit memory to proceed relatively normally in the absence of septohippocampal cholinergic input. By describing this viewpoint and its implications for the functional role of hippocampal ACh in memory, we seek to promote the idea that data from lesions are compatible with data from other experimental approaches. Furthermore, we suggest that a convergent approach that incorporates observations from different experimental methods will reveal functional characteristics of hippocampal ACh that would not be apparent from studies using a single strategy.

Before discussing the role of this system in cognition, a brief review of its anatomical and neurochemical organization is warranted. The septum is connected to the hippocampus via the fimbria-fornix, which carries projections from the medial septum

${ }^{3}$ Corresponding authors.

E-MAIL mbparent@gsu.edu; FAX (404) 651-3929.

E-MAIL mark.baxter@psy.ox.ac.uk; FAX +44 (0) 1865310447.

Article and publication are at http://www.learnmem.org/cgi/doi/10.1101/ Im.69104.
(MS, or Ch1) and the vertical limb of the diagonal band of Broca (VDB, or Ch2; Mesulam et al. 1983). These projections are predominantly cholinergic and GABAergic (Lewis et al. 1967; Köhler et al. 1984; Rye et al. 1984), although there are some neuropeptide projection neurons as well (Senut et al. 1989; Peterson and Shurlow 1992) and a putative glutamatergic projection (Sotty et al. 2003). GABAergic receptors are present on cell bodies of both cholinergic and GABAergic septohippocampal projection neurons (Gao et al. 1995; Henderson 1995). Likewise, muscarinic receptors are present on cell bodies of both cholinergic and GABAergic septohippocampal projection neurons (Van der Zee and Luiten 1994; Levey et al. 1995; Rouse and Levey 1996). Septohippocampal GABAergic projections synapse onto GABAergic hippocampal interneurons (Freund and Antal 1988), which in turn synapse onto pyramidal cells (Toth et al. 1997). Thus, GABAergic afferents to the hippocampus produce a net disinhibition of pyramidal cells. Cholinergic septohippocampal projections project broadly to the hippocampus, synapsing onto pyramidal cells, dentate granule cells, and inhibitory interneurons (Frotscher and Leranth 1985).

\section{Evidence Supporting the Involvement of Septohippocampal ACh in Memory}

Extensive data from a number of different experimental approaches suggests that the septohippocampal cholinergic system is sufficient for normal memory function. These findings include: (1) evidence for cholinergic system activation during learning and memory in intact animals, (2) a correlation between the effects of manipulations on memory and hippocampal ACh activity, and (3) reversal of memory deficits by manipulations that enhance hippocampal cholinergic function.

\section{Evidence for Cholinergic System Activation During Learning and Memory in Intact Animals}

A variety of studies have shown training-induced increases in hippocampal ACh. For instance, maze training produces a longlasting increase in hippocampal choline acetyltransferase (ChAT), the synthetic enzyme for acetylcholine (Park et al. 1992). Numerous studies have shown that hippocampal-dependent learning alters hippocampal high-affinity choline uptake (HACU), an index of cholinergic activity (Wenk et al. 1984; Decker et al. 1988; Toumane et al. 1988, 1989; Marighetto et al. 
1989, 1993, 1994; Lebrun et al. 1990; Durkin 1992, 1994; Durkin and Toumane 1992; Galey et al. 1994). More recently, in vivo microdialysis has allowed for the ability to examine changes in hippocampal extracellular ACh levels in conscious, freely moving rats during behavioral tests of learning and memory. With few exceptions (e.g., Hironaka et al. 2001), the findings of such studies show that hippocampal-dependent learning and memory is associated with an increase in hippocampal extracellular ACh levels (Yamamuro et al. 1995; Fadda et al. 1996, 2000; Orsetti et al. 1996; Ragozzino et al. 1996, 1998; Stancampiano et al. 1999; Nail-Boucherie et al. 2000; Stefani and Gold 2001; McIntyre et al. 2002, 2003; Chang and Gold 2003). Combined, the findings of these studies show that hippocampal extracellular ACh is elevated by learning and memory processes, that the elevation is often correlated with the type of learning and memory or its time course, and that these increases cannot be accounted for solely by locomotor activity or by handling. It is important to stress that these data are correlational in nature and thus do not reveal whether ACh participates in, produces, or is necessary for learning and memory. Indeed, some authors have suggested that ACh might reflect a useful marker of the extent to which a structure is engaged in mnemonic processing, rather than reflecting a specific role for ACh itself in memory (McIntyre et al. 2002; Chang and Gold 2003). This possibility is supported, for example, by the finding that hippocampal extracellular ACh levels increase in response to unconditioned or conditioned stimuli, but do not change when the same stimuli produce habituation (Acquas et al. 1996).

\section{Hippocampal ACh Activity is Correlated With Memory}

There are an overwhelming number of cases in which the effects of manipulations on memory are associated with their effects on hippocampal ACh function. For instance, aged rats that display memory deficits often display correlated decreases in hippocampal ACh markers (Lippa et al. 1980, 1985; Sherman et al. 1981; Ikegami 1994; Scali et al. 1994; Aubert et al. 1995; Baxter et al. 1999b). Chronic dietary restriction of choline (Nakamura et al. 2001) or vitamin A (Cocco et al. 2002), and chronic alcohol consumption (Arendt et al. 1990; Melis et al. 1996) produce correlated deficits in memory and hippocampal ACh. Likewise, many systemic pharmacological treatments that impair memory decrease hippocampal ACh (Hersi et al. 1995; Nava et al. 2000, 2001; Mishima et al. 2002), whereas systemic drug treatments that enhance memory increase hippocampal ACh (Levy et al. 1991; Hersi et al. 1995; Scali et al. 1997a,b; Bontempi et al. 2001; Carey et al. 2001; Kopf et al. 2001). Similar correlations are observed with intracerebroventricular (i.c.v.) manipulations (Scali et al. 1994; Hiramatsu et al. 1996; Choi et al. 2001; Olariu et al. 2001).

More importantly, a wealth of studies shows that neurochemical manipulations in the septum produce parallel changes in memory and measures of hippocampal ACh. In some instances, the correlation is such that only those doses of a drug that affect memory are those that affect hippocampal ACh (e.g., Brioni et al. 1990). Intraseptal infusions of GABA-A agonists (Brioni et al. 1990; Durkin 1992), benzodiazepine (BZD) agonists (Herzog et al. 2000), cholinergic antagonists (Givens and Olton 1990; Gorman et al. 1994), opioid agonists (Ragozzino et al. 1992; Ragozzino and Gold 1995), and noradrenergic antagonists (Marighetto et al. 1989) impair various measures of memory and hippocampal ACh activity. Interestingly, manipulations that prevent septal pharmacologically induced memory deficits also prevent the concomitant changes in hippocampal ACh. Septal infusions of glucose prevent both opioid agonist-induced decreases in memory and extracellular hippocampal ACh levels (Ragozzino and Gold 1995). Septal infusions of drugs that enhance memory, such as the neurosteroid pregnenolone sulfate (Darnaudery et al. 2002), increase hippocampal ACh. A similar pattern of findings is observed with drug infusions into the hippocampus. For instance, infusions of glucose into the hippocampus increase hippocampal extracellular ACh levels and enhance memory (Ragozzino et al. 1998).

There are instances in which the effects of septal pharmacological manipulations on memory do not parallel their effects on hippocampal ACh. For instance, septal infusions of cholinergic agonists enhance memory or reverse memory deficits (Izquierdo et al. 1992; Givens and Olton 1995; cf. Markowska et al. 1995; Pang and Nocera 1999), and would thus be expected to increase ACh function in the hippocampus. Instead, septal infusions of cholinergic agonists decrease hippocampal extracellular ACh levels (Gorman et al. 1994). Similar dissociations are observed with BZD agonists. Septal infusions of two doses of the BZD agonist chlordiazepoxide produce comparable decreases in hippocampal HACU, but only the higher dose produces amnesia (Herzog et al. 2000). Conversely, two doses of the BZD agonist zolpidem produce similar memory deficits when infused into the septum, but only one dose decreases HACU (Herzog et al. 2000). Analogous dissociations have been observed in the hippocampus. Hippocampal infusions of compounds that modulate ATPsensitive potassium channels increase hippocampal ACh release regardless of whether they enhance or impair memory (Stefani and Gold 2001). Combined, these dissociations between the neurochemical and behavioral measures raise questions about the role of hippocampal ACh in memory: Changes in memory can occur without commensurate changes in hippocampal ACh, and manipulations of the medial septum that impair memory need not necessarily affect markers of hippocampal cholinergic activity.

\section{Upregulation of Hippocampal ACh Reverses Septal Memory Deficits}

One line of research examines whether cognitive impairment after damage to or inactivation of the septum can be reversed by manipulations that increase cholinergic function. Overall, the evidence from these studies indicates that ACh is sufficient to improve mnemonic function. For example, implants of AChsecreting fibroblasts into the hippocampus attenuate cognitive deficits produced by unilateral fimbria-fornix lesions; implants into the frontal or parietal cortex are ineffective (DickinsonAnson et al. 1998). Similarly, hippocampal grafts of fetal neuronal tissue rich in cholinergic neurons reverse memory deficits produced by a variety of manipulations, including septal lesions, hippocampal lesions, bilateral fimbria-fornix lesions, or selective 192 IgG-saporin-induced lesions of the septohippocampal ACh projection (Tarricone et al. 1996; Cassel et al. 1997, 2002). Behavioral improvement is correlated with recovery of cholinergic markers (Dunnett et al. 1982; Daniloff et al. 1985; Tarricone et al. 1991, 1993) and prevented by systemic administration of cholinergic antagonists (Nilsson et al. 1987; Li et al. 1992). However, research using cholinergic grafts does not unequivocally implicate ACh in the recovery of memory. For instance, grafts can restore mnemonic function with little or no restoration of $\mathrm{ACh}$ levels (Cassel et al. 2002) or restore ACh levels without restoring cognitive function (Ipekoglu et al. 2000). Grafts that have been shown to be functional often only result in partial restoration of memory (Low et al. 1982; Pallage et al. 1986; Tarricone et al. 1996). Also, other features of cholinergic tissue grafts such as trophic factors or particular proteins may be responsible, at least in part, for functional recovery (Wets et al. 1991).

Results from pharmacological studies also show that upregulation of ACh is sufficient to reverse memory deficits. For instance, systemic administration of cholinergic agonists reverses memory deficits produced by lesions of the septum or fornix (Maho et al. 1988; Hodges et al. 1991; Decker et al. 1992; Levin et

\section{Learning \& Memory}

www.learnmem.org 
al. 1993). Memory enhancement can also sometimes be observed in the absence of a pre-existing deficit (Aigner and Mishkin 1986; Levin et al. 1993). More importantly, direct hippocampal infusions have similar effects. Specifically, hippocampal or entorhinal infusions of physostigmine, which blocks ACh degradation by inhibiting acetylcholinesterase (AChE), reverse memory deficits produced by septal infusions of the GABA-A agonist muscimol (Degroot and Parent 2000, 2001). Also, in rats given septal infusions of muscimol, intrahippocampal infusions of glucose increase hippocampal extracellular ACh (Degroot et al. 2003) and reverse memory deficits (Parent et al. 1997). Similarly, sustained hippocampal infusion of a cholinergic agonist improves memory in rats with bilateral fornix lesions (Howard III et al. 1989).

It is important to emphasize that the fact that a compound can reverse a deficit does not necessarily indicate this compound is acting at the substrate that produces the deficit. For instance, the fact that hippocampal infusions of an AChE inhibitor reverse deficits produced by septal GABA receptor activation does not necessarily imply that the GABA-induced deficit is mediated via an effect on ACh. It means only that elevating ACh is sufficient to overcome the deficit, perhaps, for example, by increasing compensatory responses (Björklund and Dunnett 1995). Indeed, the hypothesis that septal GABA receptor activation impairs memory exclusively via an effect on hippocampal ACh is not supported by the finding that septal infusions of muscimol still impair memory when the septohippocampal cholinergic projection is lesioned (Pang and Nocera 1999). On the other hand, a wealth of evidence indicates that septal GABA receptor activation does likely impair memory through a process that involves, at least in part, inhibition of hippocampal ACh. Septal infusions of muscimol decrease a variety of measures of hippocampal ACh (Blaker et al. 1983; Costa et al. 1983; Brioni et al. 1990; Gorman et al. 1994; Moor et al. 1998a), prevent training- or handling-induced increases in hippocampal ACh (Durkin 1992; Moor et al. 1998b), and modulate the dose-response properties of hippocampal infusions of cholinergic agonists on memory (Farr et al. 1999). Also, only those doses of muscimol that impair memory affect hippocampal ACh (Brioni et al. 1990).

To summarize, correlations between cholinergic activity and memory, and the ability of cholinergic agents to reverse memory deficits suggest that hippocampal ACh is involved in normal memory function. However, none of this evidence bears on the question of whether hippocampal ACh is necessary for memory. Two primary approaches have been used to address this question: first, pharmacological blockade of ACh receptors in the hippocampus, and second, direct lesions of septal cholinergic neurons. Data from studies using pharmacological approaches suggest that hippocampal ACh is necessary for normal memory, whereas data from studies of selective lesions of septal cholinergic neurons suggest that these neurons are not essential.

\section{Evidence For and Against a Necessary Role of the Cholinergic System in Memory}

\section{Antagonism of Hippocampal ACh}

The amnestic properties of anticholinergic drugs such as scopolamine and atropine have long been known (e.g., Drachman and Leavitt 1974). Systemic administration of scopolamine impairs hippocampal-dependent learning and memory in rats (Eckerman et al. 1980; Stevens 1981; Decker and Gallagher 1987). These drug effects on behavior could be mediated by structures outside the hippocampus, because ACh receptors are located throughout the central nervous system, including the hippocampus, neocortex, amygdala, thalamus, and striatum (Mash and Potter 1986; Perry and Kellar 1995). The possibility that systemic scopolamine affects memory via effects on non-hippocampal structures is supported by the finding that scopolamine can still impair memory in animals with hippocampal lesions (Richmond et al. 1997; Wan et al. 1997).

Studies that examine the effects of infusing cholinergic antagonists directly into the hippocampus bear more directly on the question of whether hippocampal cholinergic neurotransmission is necessary for learning and memory processes. Although these studies are fewer in number relative to studies of systemic anticholinergic drugs, the results of these studies indicate that intrahippocampal infusion of muscarinic antagonists (Brito et al. 1983; Izquierdo et al. 1992; Kim and Levin 1996; Carli et al. 1997, 2000; Ohno et al. 1997a,b; Gale et al. 2001; Wallenstein and Vago 2001) or nicotinic antagonists (Ohno et al. 1993; Felix and Levin 1997; Levin et al. 2002) consistently impair hippocampal-dependent memory. Combined, these findings indicate that hippocampal $\mathrm{ACh}$ is essential for normal memory function.

\section{Lesions of the Medial Septum or Its Projections}

Lesions of the fimbria-fornix, or electrolytic or neurotoxic lesions of the medial septum, impair hippocampal-dependent learning and memory (Mahut 1972; Olton et al. 1978; Mitchell et al. 1982; Rawlins and Olton 1982; Hepler et al. 1985; Kelsey and Landry 1988; Markowska et al. 1989; Kelsey and Vargas 1993). These studies have been interpreted as supporting the hypothesis that hippocampal ACh is necessary for normal memory function. However, these lesions necessarily result in loss of both cholinergic and noncholinergic septohippocampal projections. Surprisingly, findings from experiments using the immunotoxin 192 IgG-saporin to produce selective lesions of cholinergic septohippocampal neurons often fail to cause any impairment in spatial learning in the water maze, spatial working memory in the radial arm maze, or contextual fear conditioning (Berger-Sweeney et al. 1994; Torres et al. 1994; Baxter et al. 1995, 1996; Baxter and Gallagher 1996; Dornan et al. 1996; McMahan et al. 1997; Chappell et al. 1998; Kirby and Rawlins 2003; Frick et al. 2004). When impairments are observed after these selective lesions, they are rarely as great in magnitude as those observed after nonselective lesions of the septum or section of the fimbria-fornix. Thus, deficits observed after septal or fimbria-fornix lesions cannot be accounted for solely by the loss of hippocampal ACh. These latter findings have raised the unexpected possibility that hippocampal ACh is not essential for all types of hippocampal-dependent memory.

The data from 192 IgG-saporin lesions of basal forebrain cholinergic neurons are controversial, because many experiments failed to report significant behavioral impairments in common hippocampal-dependent learning and memory tasks following these lesions. However, nearly without exception, severe learning and memory impairments are found following i.c.v. administration of the toxin (Nilsson et al. 1992; BergerSweeney et al. 1994; Leanza et al. 1995, 1996; Waite et al. 1995; Walsh et al. 1995; LeBlanc et al. 1999; cf. Lehmann et al. 2000). These impairments may be due to effects on motor performance or other variables rather than effects on memory (Waite et al. 1999; Lehmann et al. 2000). Intraventricular 192 IgG-saporin lesions not only damage basal forebrain cholinergic neurons, but also cerebellar Purkinje cells (Heckers et al. 1994; Waite et al. 1995), and the motor impairments following cerebellar damage are severe (Berger-Sweeney et al. 1994; Waite et al. 1995, 1999). They are also dependent on the dose of 192 IgG-saporin (Waite et al. 1995), as would be expected if the neurotoxic action of the immunotoxin is mediated via an influence on cell populations outside the basal forebrain. The presence of concomitant cerebellar damage complicates the interpretation of results from these 
lesions as being due to a specific loss of basal forebrain cholinergic neurons, although some studies have addressed this problem by comparing effects of i.c.v. 192 IgG-saporin with those of i.c.v. OX7-saporin, a toxin that damages cerebellar Purkinje cells but not basal forebrain cholinergic neurons (Waite et al. 1999; Wrenn and Wiley 2001). OX7-saporin lesions themselves can produce severe impairments in memory as well as in motor and sensory abilities (Waite et al. 1999; Gandhi et al. 2000).

A few studies have used intraparenchymal injections of 192 IgG-saporin to produce large basal forebrain lesions that spare the cerebellum. These studies have found little (Frick et al. 2004) or no deficit (Baxter et al. 1996; Pizzo et al. 2002) in acquisition of spatial learning in the water maze or working memory in the radial arm maze (Vuckovich et al. 2004), or have found that the deficits are associated with damage that is not specific to the basal forebrain (Perry et al. 2001). Interestingly, some behavioral impairments are seen after combined damage to MS/VDB and nucleus basalis magnocellularis (NBM) cholinergic neurons that are not observed after lesions of either projection alone (Baxter et al. 1999a; Pizzo et al. 2002). These findings suggest that septohippocampal cholinergic projections may be capable of supporting memory when damage to other systems is present. These results also raise the possibility that both the basalocortical and septohippocampal projections may need to be compromised in order to produce a spatial deficit in those instances when only ACh neurons are lesioned. Such a requirement could account for the finding that systemic cholinergic antagonists impair spatial memory.

Some studies have reported significant impairment in spatial learning and memory following selective 192 IgG-saporin lesions of the MS/VDB (Shen et al. 1996; Walsh et al. 1996; Pang et al. 2001; Cassel et al. 2002; Lehmann et al. 2002a,b, 2003). However, the interpretation of these deficits as consequent to selective loss of cholinergic MS/VDB neurons is sometimes questionable. In many cases, these studies have used high doses of 192 IgG-saporin and/or injection protocols that may compromise noncholinergic MS/VDB neurons. Importantly, they have not presented histological verification of the integrity of GABAergic projection neurons at the lesion site (see also McMahan et al. 1997; Chappell et al. 1998; Baxter 2001 for discussion).

There are instances when selective 192 IgG-saporin lesions of the MS/VDB produce deficits, and the integrity of GABAergic projection neurons at the lesion site is documented. It is important to note that when memory deficits are reported after damage limited to septohippocampal cholinergic projections, those deficits are often smaller in comparison to deficits observed after damage to the hippocampus or fornix, or after systemic cholinergic blockade. This suggests that when a spatial memory test does exert a specific requirement on septohippocampal cholinergic projections, this requirement is limited. Furthermore, when impairments are seen in memory tasks after cholinergic lesions, they may be caused by an influence on a nonmnemonic process. Lehmann and colleagues (2003) found that 192 IgG-saporin lesions of the MS/VDB induced prior to training in a spatial radial arm maze task impaired acquisition performance. However, because the lesions were induced before training, further studies are needed to determine whether the deficits reflect a spatial learning deficit or an impairment in another process, such as a component of attention. Cholinergic MS/VDB lesions produce a delay-independent impairment in matching-to-place in the water maze, although the deficit may be attentional because it does not vary with the training-retention interval (Baxter et al. 1995). Impairments have also been reported in acquisition and performance of a delayed matching-to-place task in the T-maze (Gibbs 2002; Johnson et al. 2002) following lesions limited to MS/VDB cholinergic neurons. However, nonmatching-to-place in the T- maze is not impaired following MS/VDB cholinergic lesions (Pang and Nocera 1999; Kirby and Rawlins 2003). Because the memory requirement in the two tasks is equivalent, the matching deficits may reflect an inability to apply a behavioral rule that is contrary to the rat's spontaneous nonmatching behavior, rather than an impairment in spatial memory per se.

Selective septohippocampal ACh lesions also produce retrograde amnesia for socially transmitted food preferences, a form of nonspatial paired-associate learning (Vale-Martínez et al. 2002). These lesions also impair memory for postoperatively learned associations if learning is made difficult by presenting only a single acquisition trial (Berger-Sweeney et al. 2000) or by increasing the number of choice alternatives at the retention test, which possibly reflects a retrieval deficit (Vale-Martínez et al. 2002). However, because intact learning and memory for these associations can also be observed in some test situations (Vale-Martínez et al. 2002), it seems that cholinergic input to the hippocampus is not always essential for this form of paired-associate learning. Impairments in conditional associative learning tasks are also seen after lesions of MS/VDB cholinergic neurons (Ridley et al. 1999; Janisiewicz et al. 2004). However, when conditional tasks are presented with computer-graphic, two-dimensional stimuli, impairments in visual-spatial conditional learning are not observed consistently, and their presence appears to reflect an impairment in the transfer of behavioral rules from previously learned discrimination problems (Janisiewicz and Baxter 2003). Taken together, these findings imply that selective damage to cholinergic afferents to the hippocampus can affect memory and other aspects of cognitive processing, but these deficits are limited to a subset of cognitive processes dependent on the hippocampus. Indeed, it is not surprising that selective damage to a subset of hippocampal afferents does not produce an effect equivalent to that of a hippocampal lesion. We speculate on the possible specific role(s) of hippocampal ACh in a later section.

\section{Can Compensation or Insufficient Lesion Size Explain Negative Effects of $192 \lg$ G-saporin Lesions?}

Because the finding that lesions limited to septohippocampal cholinergic projections produce minimal deficits in spatial learning and memory is at odds with the evidence reviewed above in favor of a role of hippocampal ACh in memory, it is essential to rule out the possibility that there is a methodological problem with the 192 IgG-saporin data. Given that these studies involve lesions, they assume the same limitations of any lesion study. Specifically, the absence of a lesion effect could be due to the possibility that the lesion was not extensive enough to produce a behavioral effect, that normal memory is mediated by compensatory changes produced by the lesions, or both.

192 IgG-saporin lesions of the MS/VDB do not produce complete destruction of hippocampal ACh. Hippocampal ChAT is commonly used as a quantitative measure of lesion extent, although histochemistry for AChE has also been employed (McGaughy et al. 1996; Wrenn et al. 1999). These enzyme measures correlate positively with the number of basal forebrain neurons remaining after the lesion (Leanza et al. 1995; Wrenn et al. 1999; McGaughy et al. 2002). However, because neither enzyme is the rate-limiting step for ACh synthesis or release, it is possible that ChAT and AChE measures overestimate the functional extent of the lesion. Studies examining the effects of 192 IgG-saporin lesions of the MS/VDB commonly report 70\%-90\% loss of hippocampal ChAT activity, reflecting a loss of cholinergic terminals. This $90 \%$ may reflect the sensitivity limit of the assay, or it may indicate that some projections remain and could mediate the spared retention that is observed in rats given 192 IgG-saporin lesions of the MS/VDB. There are data suggesting that ACh syn-

\section{Learning \& Memory}

www.learnmem.org 
thesis in remaining neural elements in the hippocampus may increase to compensate for the loss of projections (Waite and Chen 2001; Chang and Gold 2002). However, there is also evidence to the contrary indicating that 192 IgG-saporin lesions virtually abolish evoked ACh release from hippocampal slices (Birthelmer et al. 2002, 2003). As in the case of fimbria-fornix lesions (Westlind et al. 1981; Dawson et al. 1989), selective septohippocampal ACh lesions may also produce an increase in the number of postsynaptic muscarinic receptors (Roßner et al. 1995; Sorger et al. 1999; cf. Potter et al. 1999). Another possibility is that compensation occurs through the engagement of other neurotransmitter or neural systems, which could substitute for the deficiency in hippocampal ACh. Also, there are intrinsic cholinergic interneurons in the hippocampus (Frotscher et al. 1986; Frotscher 1988) that would not likely be affected by MS/VDB infusions of 192 IgG-saporin. However, these neurons do not appear to compensate for the loss of cholinergic input to the hippocampus that follows fimbria-fornix section (Frotscher 1988), so presumably they also would not compensate following loss of cholinergic input due to 192 IgG-saporin lesions.

There are several lines of evidence that suggest that insufficient lesion size or compensatory reorganization cannot account for the normal memory observed in animals with selective cholinergic lesions. First, nonspecific neurotoxic lesions which damage both noncholinergic and cholinergic septal neurons impair memory, yet produce less depletion of hippocampal ACh than do the selective lesions. For instance, Hagan et al. (1988) reported impairments in spatial learning in rats with ibotenic acid lesions of the medial septum that reduced hippocampal ChAT activity by $70 \%$. In contrast, Baxter et al. (1995) found no impairment in spatial learning in rats with immunolesions of the MS/VDB that reduced hippocampal ChAT activity by $90 \%$.

Second, it is also not clear how either compensation or insufficient lesion magnitude can account for the finding that cholinergic septal lesions are capable of producing significant behavioral impairments in other measures. For example, removal of septohippocampal cholinergic neurons impairs latent inhibition, which indexes the ability to reduce attention to a pre-exposed stimulus. Furthermore, the impairment produced by the cholinergic lesions is as severe as that produced by neurotoxic hippocampal lesions (Han et al. 1995; Baxter et al. 1997). Similar deficits are observed in other paradigms that assess the ability to reduce attention to conditioned stimuli (Baxter et al. 1997, 1999c). The instances in which lesions are and are not effective cannot be accounted for by between-subject differences because the same rats that are impaired in the latent inhibition test (Baxter et al. 1997) did not have any deficits in a previous test of spatial memory in the Morris water maze (Baxter et al. 1995). Compensation would be expected to produce the opposite pattern, with tests given closer to the time of the lesion showing greater impairment than tests given later. It is also not clear how compensation and insufficient lesion size could affect some hippocampal-dependent tasks and not others. The possibility remains, though, that spatial cognition is more resilient to loss of hippocampal cholinergic input than are other functions of the hippocampus. Combined, these findings indicate that it is unlikely that selective cholinergic lesions do not impair memory because they do not produce a threshold depletion of $\mathrm{ACh}$, or because the lesions produce compensatory reorganization that mediates the spared memory. Moreover, these findings suggest that the impairment seen after nonspecific neurotoxic lesions cannot solely be due to the loss of cholinergic neurons, even though much of the data from neurotoxic lesion experiments were interpreted in this way initially. They also support the hypothesis that there is only a subset of hippocampal-dependent tasks that require ACh to be performed efficiently.
To resolve definitively the question of necessity of cholinergic MS/VDB neurons in memory would require the ability to selectively and reversibly inactivate cholinergic neurons in the MS/VDB, but there is apparently currently no means of doing this. Such experiments would address the question of whether 192 IgG-saporin lesions typically fail to impair memory because the permanent nature of the lesion permits the development of compensatory changes. Although studies of intraseptal infusions of cholinergic agents are often discussed in the context of their effects on cholinergic neurons, muscarinic receptors are present on both cholinergic and GABAergic projection neurons (Van der Zee and Luiten 1994; Levey et al. 1995; Rouse and Levey 1996). Moreover, muscarinic agents seem to predominantly modulate GABAergic projections from the MS/VDB to the hippocampus rather than the cholinergic projection (Alreja et al. 2000b; Wu et al. 2000). Therefore, these studies shed little light on the question of whether septohippocampal cholinergic projections are necessary for learning and memory. Another important strategy would be to systematically characterize the functional capacity of hippocampal ACh following 192 IgG-saporin lesions of cholinergic projections to the hippocampus. For example, it would be useful to combine in vivo microdialysis procedures with behavioral analyses in 192 IgG saporin-lesioned rats to examine the extent to which ACh release occurs in memory tasks that are and are not impaired by the lesions. Some progress has already been made in this regard; Chang and Gold (2002) reported some preliminary findings indicating that rats with 192 IgG-saporin lesions of the MS/VDB were impaired on spontaneous alternation, but that there was residual hippocampal ACh release in these rats. In fact, the behaviorally induced increase in ACh relative to baseline was higher in lesioned rats than in controls.

\section{DISCUSSION}

We have discussed evidence that the presence of hippocampal $\mathrm{ACh}$ is sufficient to support many forms of learning and memory following disruption of the septohippocampal system. Furthermore, changes in hippocampal cholinergic markers and memory are frequently highly correlated with one another. These findings indicate that hippocampal ACh is involved in memory or at the very least, that it has the capacity to participate. However, septohippocampal cholinergic neurons do not appear to be necessary for many aspects of hippocampal-dependent memory, as performance on many spatial learning and memory tasks survives the loss of these neurons. Rather than discounting the data from 192 IgG-saporin lesions because they are not congruent with observations made from other experimental approaches, we suggest that they can be viewed as contributing to the specific question of whether cholinergic neurons are necessary for memory function, and for which functions they may be necessary. This distinction between necessity and sufficiency/ involvement is hardly a novel one (e.g., Berntson et al. 1996; Martin et al. 2000), but it has not been widely considered in analyses of the role of septohippocampal ACh in memory (cf. Pang and Nocera 1999; Baxter and Murg 2002; McIntyre et al. 2002).

\section{Remaining Issues}

One question that remains is the mismatch between the effects of infusions of cholinergic antagonists into the hippocampus, which impair memory, versus the effects of selective lesions of MS/VDB cholinergic neurons, which remove cholinergic projections to the hippocampus but produce limited effects on learning and memory. It is remarkable that infusions of cholinergic antagonists into the hippocampus can produce such large deficits in memory. Experiments with neurotoxic lesions of the hippo- 
campus suggest that at least $20 \%$ of hippocampal volume must be damaged to produce spatial learning impairments (Moser et al. 1993), yet cholinergic antagonists produce deficits while having a more spatially and temporally limited effect on hippocampal function than do lesions. One possibility is that intrahippocampal drug infusions exert effects that are not limited to cholinergic receptor blockade. For example, they may produce a local anesthetic effect or disrupt other neurotransmitter systems, although there is apparently no evidence for these possibilities. Another possibility is that disturbance of a limited area of the hippocampus is more deleterious to memory than large-scale disruption (Solomon et al. 1983; Baxter and Murray 2001). That is, the output of a dysfunctional hippocampus may produce more cognitive deficits than would the absence of hippocampal processing. Finally, the discrepancy between the effects of antagonists and lesions could reflect compensatory changes that occur with permanent lesions but not with transient pharmacological manipulations. However, we have already discussed the evidence indicating why this is not a likely explanation.

It is possible that the absence of impairment in spatial learning tasks (such as the radial arm maze or water maze) following lesions of MS/VDB cholinergic neurons reflects the fact that there are multiple strategies available for correctly solving these tasks, only some of which are affected by removal of hippocampal cholinergic input. This may make spatial learning tasks more resistant to the loss of hippocampal cholinergic input, relative to other behaviors that may specifically require a certain aspect of hippocampal-dependent information processing such as decreases in the associability of conditioned stimuli (Baxter et al. 1997, 1999c). For example, rats may use egocentric (body movement) cues, path integration, orientation to single visual cues, spatial maps, or any combination thereof to solve such problems (Whishaw et al. 1995; Dudchenko et al. 1997; Martin et al. 1997; Maaswinkel and Whishaw 1999; Maaswinkel et al. 1999; Dudchenko 2001). Two studies have suggested that lesions of MS/ VDB cholinergic neurons bias rats away from using an allocentric (place) strategy to solve a radial arm maze (Janis et al. 1998; Lehmann et al. 2003), although other studies have found that rats with these lesions are able to use such strategies in the crossmaze (Cahill and Baxter 2001) or water maze (Bizon et al. 2003). Examination of particular strategies used by animals to solve spatial problems might represent a fruitful avenue of investigation, as selective neurochemical lesions may be able to reveal how spatial cognition is fractionated within the hippocampus.

The involvement of noncholinergic septohippocampal projections in memory remains unspecified. Electrophysiological studies show that muscarinic agonists and antagonists and opioid agonists preferentially act at the septohippocampal GABAergic projection (Alreja et al. 2000a,b; Wu et al. 2000). These findings suggest that infusions of these agents into the medial septum may exert their effects on memory by affecting GABAergic rather than cholinergic septohippocampal projections. However, it is worth noting that these studies are performed in brain slices from very young (2-4-wk-old) rats, so it will be important to confirm the physiology of the septohippocampal GABA projections in adult rats. Computational modeling suggests that GABA, acting via $\mathrm{GABA}(\mathrm{B})$ receptors, possesses the capacity to rapidly modulate hippocampal physiology on a time scale consistent with spatial learning (Wallenstein and Hasselmo 1997; Hasselmo and Fehlau 2001; Molyneaux and Hasselmo 2002). Ibotenic acid lesions of the MS/VDB, which primarily affect the septal GABA neurons but spare the ACh neurons, impair place learning (Cahill and Baxter 2001). In contrast, selective kainic acid-induced lesions of the septohippocampal GABA projection do not impair spatial learning, suggesting that the septal GABAergic projection is also not necessary for memory (Pang et al. 2001). The discrep- ancy between the effects of GABA lesions in these latter two studies may be related to the presence of damage to the peptidergic component of the septohippocampal projection, which was not assessed. Indeed, the contributions of the peptidergic and putative glutamatergic septohippocampal projections to memory warrant further investigation. The combined findings that fornix lesions impair memory and that selective cholinergic and GABAergic septal lesions do not raise the possibility that combined damage to cholinergic and noncholinergic septal projection neurons might be necessary to impair hippocampaldependent memory. In support of this, selective lesions of the septal GABA projection do impair memory when combined with 192 IgG-saporin lesions of the cholinergic projection (Pang et al. 2001).

Attentional deficits are reliably observed after selective loss of basal forebrain cholinergic neurons, both in the MS/VDB and in the NBM/substantia inominata (McGaughy et al. 1996, 2002; Baxter et al. 1997, 1999c; Sarter et al. 1997, 1999; McGaughy and Sarter 1998). Subtle effects of ACh on memory could be mediated by changes in attentional processing, and this may help explain some of the inconsistencies. Lesions of corticopetal cholinergic projections (from the NBM) also often impair performance on a variety of attentional tasks (McGaughy et al. 1996, 2002; Lehmann et al. 2003) without substantially affecting memory (e.g., Baxter et al. 1995; Dornan et al. 1996; Galani et al. 2002). These findings indicate that impairments in attention following basal forebrain cholinergic lesions must exert relatively circumscribed effects on the overall efficiency of cognitive processing in order for learning and memory to proceed in the presence of impaired attentional processing. These lesions might be better characterized as disrupting the ability to regulate attentional resources, rather than the capacity to attend to stimuli per se (Baxter and Chiba 1999; Baxter and Murg 2002). Memory tasks that include an increased burden on attention, or require a specific mode of information processing, should be more sensitive to loss of basal forebrain cholinergic neurons (e.g., Turchi and Sarter 2000). However, the presence of dissociations between mnemonic and attentional performance following basal forebrain cholinergic damage suggests that many memory processes, which are involved in consolidation, storage, and retrieval, as well as encoding, can operate normally in the absence of cholinergic input (see also Sarter et al. 2003). In the context of this discussion, it is important to be mindful that there are many different varieties of attentional processing, just as there are different systems for different kinds of memory (Muir 1996; Bushnell 1998; Sarter and McGaughy 1998). Thus, the demonstration of a dissociation between a particular aspect of attentional processing and memory performance following septohippocampal ACh lesions (e.g., Lehmann et al. 2003) does not necessarily imply that other aspects of attention are also intact following the lesions (cf. Baxter et al. 1997, 1999c).

\section{Conclusion}

In summary, the findings that cholinergic activity in the hippocampus is correlated with memory, and restoration of ACh in the hippocampus after disruption of the septohippocampal pathway is sufficient to rescue memory, indicate that hippocampal ACh is involved in memory. However, selective ablation of cholinergic septohippocampal projections produces minimal effects on hippocampal-dependent learning and memory processes, suggesting that although hippocampal ACh may promote memory in the intact brain, it is not necessary for many aspects of hippocampal memory function.

These combined findings raise the possibility that hippocampal ACh may have a modulatory role in memory, analogous

\section{Learning \& Memory}

www.learnmem.org 
to the contributions of the amygdala. Amygdala activation enhances different types of memory (Packard et al. 1994; McGaugh et al. 2000), yet lesions of the amygdala are without effect on many of the same tasks (McDonald and White 1993; Decker et al. 1995). It has been suggested that like the amygdala, ACh in hippocampus and other brain regions may play a modulatory role in memory, perhaps coordinating the contributions of different memory systems (McIntyre et al. 2002, 2003). Several lines of evidence are consistent with a modulatory role of hippocampal ACh. For instance, intrahippocampal infusions of ACh agonists enhance hippocampal-dependent memory (Izquierdo et al. 1992; Farr et al. 1999, 2000). Also, ACh increases the effectiveness of other inputs in stimulating action potentials in hippocampal neurons (for review, see Ridley et al. 1991). Via hippocampal muscarinic receptors, ACh increases cytosolic calcium and amplifies action potential-induced calcium changes (Woolf 1996; Power and Sah 2002). Notably, hippocampal muscarinic receptors are not necessary for long-term potentiation, but do facilitate it (Abe et al. 1994). Thus, cholinergic systems may be engaged during learning and memory and may modulate memory, but learning and memory may proceed relatively normally in their absence.

The combined findings from studies examining the effects of 192 IgG-saporin lesions indicate that a small subset of hippocampal-dependent behavioral tasks are affected by the lesions. This raises the question of how to characterize the processes that require hippocampal ACh. One possibility is that hippocampal ACh may lend flexibility to higher-order learning, such as the application of behavioral rules and transfer of experience across behavioral problems (Sarter et al. 2002; Janisiewicz and Baxter 2003). Thus, it may be generally involved in the flexibility of memory expression in the hippocampal system (Reber et al. 1996; Myers et al. 2002). Further evidence in support of this view comes from studies of place cell activity in the hippocampus after 192 IgG-saporin lesions of the MS/VDB. Place cells in rats with cholinergic lesions show equivalent electrophysiological properties and spatial selectivity, but their spatial firing patterns are less flexible than those of controls when the local environment is altered (Ikonen et al. 2002). It is worth noting that this place cell inflexibility does not seem to be related to spatial learning impairments in rats with similar lesions (Baxter et al. 1995; Janisiewicz et al. 2004). This role for hippocampal ACh in flexibility of memory representations might also be related to a general role for ACh in restructuring cortical sensory and motor representations as a consequence of learning (Bakin and Weinberger 1996; Kilgard and Merzenich 1998; Conner et al. 2003).

These views have implications for understanding the role of cholinergic deficiency in disorders of memory, including Alzheimer's disease (Davies 1999; Davis et al. 1999), as well as for the ability of cholinergic drug therapies to improve memory (Baxter and Gallagher 1997; Bartus 2000). Because loss of cholinergic neurons does not seem to be a sufficient basis to explain memory impairment in normal aging or neurodegenerative disease, other neurobiological substrates of this decline must be identified (Gallagher et al. 2003; Rosenzweig and Barnes 2003). Understanding how these other mechanisms might be necessary for memory may lead to new therapies for memory impairment. Consideration of the mechanisms by which hippocampal ACh can modulate memory, and the aspects of memory for which it may be necessary, may also lead to new strategies for memory improvement, as well as to a better understanding of the fundamental neurobiology of memory function in the hippocampus.

\section{ACKNOWLEDGMENTS}

We thank Dr. Karyn Frick and the anonymous referees for critical comments on an earlier version of this manuscript. Supported by
NINDS-NIDDK-JDF R01-NS41173 and NSF IBN-9876754 (M.B.P.) and an Alfred P. Sloan fellowship (M.G.B.).

\section{REFERENCES}

Abe, K., Nakata, A., Mizutani, A., and Saito, H. 1994. Facilitatory but nonessential role of the muscarinic cholinergic system in the generation of long-term potentiation of population spikes in the dentate gyrus in vivo. Neuropharmacol. 33: 847-852.

Acquas, E., Wilson, C., and Fibiger, H.C. 1996. Conditioned and unconditioned stimuli increase frontal cortical and hippocampal acetylcholine release: Effects of novelty, habituation, and fear. $J$. Neurosci. 16: 3089-3096.

Aigner, T.G. and Mishkin, M. 1986. The effects of physostigmine and scopolamine on recognition memory in primates. Behav. Neural Biol. 45: $81-87$.

Alreja, M., Shanabrough, M., Liu, W., and Leranth, C. 2000a. Opioids suppress IPSCs in neurons of the rat medial septum/diagonal band of Broca: Involvement of $\mu$-opioid receptors and septohippocampal GABAergic neurons. J. Neurosci. 20: 1179-1189.

Alreja, M., Wu, M., Liu, W., Atkins, J.B., Leranth, C., and Shanabrough, M. 2000b. Muscarinic tone sustains impulse flow in the septohippocampal GABA but not cholinergic pathway: Implications for learning and memory. J. Neurosci. 20: 8103-8110.

Arendt, T., Schugens, M.M., and Bigl, V. 1990. The cholinergic system and memory: Amelioration of ethanol-induced memory deficiency by physostigmine in rat. Acta Neurobiol. Exp. 50: 251-262.

Aubert, I., Rowe, W., Meaney, M.J., Gauthier, S., and Quirion, R. 1995. Cholinergic markers in aged cognitively impaired Long-Evans rats. Neuroscience 67: 277-292.

Bakin, J.S. and Weinberger, N.M. 1996. Induction of a physiological memory in the cerebral cortex by stimulation of the nucleus basalis. Proc. Natl. Acad. Sci. 93: 11219-11224.

Bartus, R.T. 2000. On neurodegenerative diseases, models, and treatment strategies: Lessons learned and lessons forgotten a generation following the cholinergic hypothesis. Exp. Neurol. 163: 495-529.

Baxter, M.G. 2001. Effects of selective immunotoxic lesions on learning and memory. In Methods in molecular biology Vol. 166: Immunotoxin methods and protocols, (ed. W.A. Hall), pp. 249-265. Humana Press, Totowa, NJ.

Baxter, M.G. and Chiba, A.A. 1999. Cognitive functions of the basal forebrain. Curr. Opin. Neurobiol. 9: 178-183.

Baxter, M.G. and Gallagher, M. 1996. Intact spatial learning in both young and aged rats following selective removal of hippocampal cholinergic input. Behav. Neurosci. 110: 460-467.

. 1997. Cognitive effects of selective loss of basal forebrain cholinergic neurons: Implications for cholinergic therapies of Alzheimer's disease. In Pharmacological treatment of Alzheimer's disease: Molecular and neurobiological foundations (eds. J.D. Brioni and M.W. Decker), pp. 87-103. Wiley, New York.

Baxter, M.G. and Murg, S.L. 2002. The basal forebrain cholinergic system and memory: Beware of dogma. In Neuropsychology of memory (eds. L.R. Squire and D.L. Schacter), 3rd Ed., pp. 425-436. Guilford Press, New York.

Baxter, M.G. and Murray, E.A. 2001. Opposite relationship of hippocampal and rhinal cortex damage to delayed nonmatching-to-sample deficits in monkeys. Hippocampus 11: 61-71.

Baxter, M.G., Bucci, D.J., Gorman, L.K., Wiley, R.G., and Gallagher, M. 1995. Selective immunotoxic lesions of basal forebrain cholinergic cells: Effects on learning and memory in rats. Behav. Neurosci. 109: 714-722.

Baxter, M.G., Bucci, D.J., Sobel, T.J., Williams, M.J., Gorman, L.K., and Gallagher, M. 1996. Intact spatial learning following lesions of basal forebrain cholinergic neurons. NeuroReport 7: 1417-1420.

Baxter, M.G., Bucci, D.J., Holland, P.C., and Gallagher, M. 1999a. Impairments in conditioned stimulus processing and conditioned responding after combined selective removal of hippocampal and cortical cholinergic input. Behav. Neurosci. 113: 486-495.

Baxter, M.G., Frick, K.M., Price, D.L., Breckler, S.J., Markowska, A.L., and Gorman, L.K. 1999b. Presynaptic markers of cholinergic function in the rat brain: Relationship with age and cognitive status. Neuroscience 89: 771-779.

Baxter, M.G., Gallagher, M., and Holland, P.C. 1999c. Blocking can occur without losses in attention in rats with selective lesions of hippocampal cholinergic input. Behav. Neurosci. 113: 881-890.

Baxter, M.G., Holland, P.C., and Gallagher, M. 1997. Disruption of decrements in conditioned stimulus processing by selective removal of hippocampal cholinergic input. J. Neurosci. 17: 5230-5236.

Berger-Sweeney, J., Heckers, S., Mesulam, M.-M., Wiley, R.G., Lappi, D.A., and Sharma, M. 1994. Differential effects on spatial navigation of immunotoxin-induced cholinergic lesions of the medial septal area and nucleus basalis magnocellularis. J. Neurosci. 14: 4507-4519. 
Berger-Sweeney, J., Stearns, N.A., Frick, K.M., Beard, B., and Baxter, M.G. 2000. Cholinergic basal forebrain is critical for social transmission of food preferences. Hippocampus 10: 729-738.

Berntson, G.G., Hart, S., Ruland, S., and Sarter, M. 1996. A central cholinergic link in the cardiovascular effects of the benzodiazepine receptor partial inverse agonist FG 7142. Behav. Brain Res. 74: 91-103.

Birthelmer, A., Dommes, E., Jeltsch, H., Cassel, J.C., and Jackisch, R. 2002. Septal grafts and evoked acetylcholine release in the rat hippocampus after 192 IgG-saporin lesions. NeuroReport 13: 973976.

Birthelmer, A., Ehret, A., Amtage, F., Forster, S., Lehmann, O., Jeltsch, H., Cassel, J.C., and Jackisch, R. 2003. Neurotransmitter release and its presynaptic modulation in the rat hippocampus after selective damage to cholinergic or/and serotonergic afferents. Brain Res. Bull. 59: $371-381$

Bizon, J.L., Han, J.-S., Hudon, C., and Gallagher, M. 2003. Effects of hippocampal cholinergic deafferentation on learning strategy selection in a visible platform version of the water maze. Hippocampus 13: 676-684.

Björklund, A. and Dunnett, S.B. 1995. Acetylcholine revisited. Nature 375: 446.

Blaker, W.D., Cheney, D.L., Gandolfi, O., and Costa, E. 1983. Simultaneous modulation of hippocampal cholinergic activity and extinction by intraseptal muscimol. J. Pharm. Exp. Ther. 225: 361-365.

Bontempi, B., Whelan, K.T., Risbrough, V.B., Rao, T.S., Buccafusco, J.J., Lloyd, G.K., and Menzaghi, F. 2001. SIB-1553A, (+/-)-4-[[2-(1-methyl-2-pyrrolidinyl)ethyl]thio]phenol hydrochloride, a subtype-selective ligand for nicotinic acetylcholine receptors with putative cognitive-enhancing properties: Effects on working and reference memory performance in aged rodents and nonhuman primates. J. Pharm. Exp. Ther. 299: 297-306.

Brioni, J.D., Decker, M.W., Gamboa, L.P., Izquierdo, I., and McGaugh, J.L. 1990. Muscimol injections into the medial septum impair spatial learning. Brain Res. 522: 227-234.

Brito, G.N., Davis, B.J., Stopp, L.C., and Stanton, M.E. 1983. Memory and the septo-hippocampal cholinergic system in the rat. Psychopharmacol. 81: 315-320.

Bushnell, P.J. 1998. Behavioral approaches to the assessment of attention in animals. Psychopharmacol. 138: 231-259.

Cahill, J.F.X. and Baxter, M.G. 2001. Cholinergic and noncholinergic septal neurons modulate strategy selection in spatial learning. Eur. J. Neurosci. 14: $1856-1864$.

Carey, G.J., Billard, W., Binch III, H., Cohen-Williams, M., Crosby, G., Grzelak, M., Guzik, H., Kozlowski, J.A., Lowe, D.B., Pond, A.J., et al. 2001. SCH 57790, a selective muscarinic M(2) receptor antagonist, releases acetylcholine and produces cognitive enhancement in laboratory animals. Eur. J. Pharmacol. 431: 189-200.

Carli, M., Luschi, R., and Samanin, R. 1997. Dose-related impairment of spatial learning by intrahippocampal scopolamine: Antagonism by ondansetron, a 5-HT3 receptor antagonist. Behav. Brain Res. 82: $185-194$.

Carli, M., Balducci, C., and Samanin, R. 2000. Low doses of 8-OH-DPAT prevent the impairment of spatial learning caused by intrahippocampal scopolamine through 5-HT(1A) receptors in the dorsal raphe. Brit. J. Pharmacol. 131: 375-381.

Cassel, J.-C., Duconseille, E., Jeltsch, H., and Will, B. 1997. The fimbria-fornix/cingular bundle pathways: A review of neurochemical and behavioral approaches using lesions and transplantation techniques. Prog. Neurobiol. 51: 663-716.

Cassel, J.-C., Gaurivaud, M., Lazarus, C., Bertrand, F., Galani, R., and Jeltsch, H. 2002. Grafts of fetal septal cells after cholinergic immunotoxic denervation of the hippocampus: A functional dissociation between dorsal and ventral implantation sites. Neuroscience 113: 871-882.

Chang, Q. and Gold, P.E. 2002. Residual hippocampal cholinergic functions after $192 \mathrm{IgG}$-saporin lesions of the medial septum/ventral diagonal band (MS/VDB). Program No. 82.8. http://sfn.scholarone.com

- 2003. Switching memory systems during learning: Changes in patterns of brain acetylcholine release in the hippocampus and striatum in rats. J. Neurosci. 23: 3001-3005

Chappell, J., McMahan, R., Chiba, A., and Gallagher, M. 1998. A re-examination of the role of basal forebrain cholinergic neurons in spatial working memory. Neuropharmacol. 37: 481-487.

Choi, S., Park, C., Koo, J., Seo, J., Kim, H., Jeong, S., Lee, J., Kim, S., and Suh, Y. 2001. Memory impairment and cholinergic dysfunction by centrally administered $\mathrm{Ab}$ and carboxyl-terminal fragment of Alzheimer's APP in mice. FASEB J. 15: 1816-1818.

Cocco, S., Diaz, G., Stancampiano, R., Diana, A., Carta, M., Curreli, R., Sarais, L., and Fadda, F. 2002. Vitamin A deficiency produces spatial learning and memory impairments in rats. Neuroscience 115: $475-482$.

Conner, J.M., Culberson, A., Packowski, C., Chiba, A.A., and Tuszynski, M.H. 2003. Lesions of the basal forebrain cholinergic system impair task acquisition and abolish cortical plasticity associated with motor skill learning. Neuron 38: 819-829.

Costa, E., Panula, P., Thompson, H.K., and Cheney, D.L. 1983. The transsynaptic regulation of the septal-hippocampal cholinergic neurons. Life Sci. 32: 165-179.

Daniloff, J.K., Bodony, R.P., Low, W.C., and Wells, J. 1985. Cross-species embryonic septal transplants: Restoration of conditioned learning behavior. Brain Res. 346: 176-180.

Darnaudery, M., Pallares, M., Piazza, P.V., Le Moal, M., and Mayo, W. 2002. The neurosteroid pregnenolone sulfate infused into the medial septum nucleus increases hippocampal acetylcholine and spatial memory in rats. Brain Res. 951: 237-242.

Davies, P. 1999. Challenging the cholinergic hypothesis in Alzheimer disease. JAMA 281: 1433-1434.

Davis, K.L., Mohs, R.C., Marin, D., Purohit, D.P., Perl, D.P., Lantz, M., Austin, G., and Haroutunian, V. 1999. Cholinergic markers in elderly patients with early signs of Alzheimer disease. JAMA 281: 1401-1406.

Dawson, V.L., Gage, F.H., Hunt, M.A., and Wamsley, J.K. 1989. Normalization of subtype-specific muscarinic receptor binding in the denervated hippocampus by septodiagonal band grafts. Exp. Neurol. 106: $115-124$

Decker, M.W. and Gallagher, M. 1987. Scopolamine-disruption of radial arm maze performance: Modification by noradrenergic depletion. Brain Res. 417: 59-69.

Decker, M.W., Pelleymounter, M.A., and Gallagher, M. 1988. Effects of training on a spatial memory task on high affinity choline uptake in hippocampus and cortex in young adult and aged rats. J. Neurosci. 8: $90-99$.

Decker, M.W., Majchrzak, M.J., and Anderson, D.J. 1992. Effects of nicotine on spatial memory deficits in rats with septal lesions. Brain Res. 572: 281-285.

Decker, M.W., Curzon, P., and Brioni, J.D. 1995. Influence of separate and combined septal and amygdala lesions on memory, acoustic startle, anxiety, and locomotor activity in rats. Neurobiol. Learn. Mem. 64: 156-168.

Degroot, A. and Parent, M.B. 2000. Increasing acetylcholine levels in the hippocampus or entorhinal cortex reverses the impairing effects of septal GABA receptor activation on spontaneous alternation. Learn. Mem. 7: 293-302.

. 2001. Infusions of physostigmine into the hippocampus or the entorhinal cortex attenuate avoidance retention deficits produced by intra-septal infusions of the GABA agonist muscimol. Brain Res. 920: $10-18$.

Degroot, A., Kornecook, T., Quirion, R., DeBow, S., and Parent, M.B. 2003. Glucose increases hippocampal extracellular acetylcholine levels upon activation of septal GABA receptors. Brain Res. 979: $71-77$.

Dickinson-Anson, H., Aubert, I., Gage, F.H., and Fisher, L.J. 1998. Hippocampal grafts of acetylcholine-producing cells are sufficient to improve behavioural performance following a unilateral fimbria-fornix lesion. Neuroscience 84: 771-781.

Dornan, W.A., McCampbell, A.R., Tinkler, G.P., Hickman, L.J., Bannon, A.W., Decker, M.W., and Gunther, K.L. 1996. Comparison of site-specific injections into the basal forebrain on water maze and radial arm maze performance in the male rat after immunolesioning with 192 IgG saporin. Behav. Brain Res. 82: 93-101.

Drachman, D. and Leavitt, J.L. 1974. Human memory and the cholinergic system: A relationship to aging? Arch. Neurol. 30: 113-121.

Dudchenko, P.A. 2001. How do animals actually solve the T maze? Behav. Neurosci. 115: 850-860.

Dudchenko, P.A., Goodridge, J.P., Seiterle, D.A., and Taube, J.S. 1997. Effects of repeated disorientation on the acquisition of spatial tasks in rats: Dissociation between the appetitive radial arm maze and aversive water maze. J. Exp. Psychol. Anim. Behav. Process. 23: $194-210$.

Dunnett, S.B., Low, W.C., Iversen, S.D., Stenevi, U., and Bjorklund, A. 1982. Septal transplants restore maze learning in rats with fornix-fimbria lesions. Brain Res. 251: 335-348.

Durkin, T.P. 1992. GABAergic mediation of indirect transsynaptic control over basal and spatial memory testing-induced activation of septo-hippocampal cholinergic activity in mice. Behav. Brain Res. 50: $155-165$.

1994. Spatial working memory over long retention intervals: Dependence on sustained cholinergic activation in the septohippocampal or nucleus basalis magnocellularis-cortical pathways? Neuroscience 62: 681-693.

\section{Learning \& Memory


Durkin, T.P. and Toumane, A. 1992. Septo-hippocampal and nBM-cortical cholinergic neurones exhibit differential time-courses of activation as a function of both type and duration of spatial memory testing in mice. Behav. Brain Res. 50: $43-52$.

Eckerman, D.A., Gordon, W.A., Edwards, J.D., MacPhail, R.C., and Gage, M.I. 1980. Effects of scopolamine, pentobarbital, and amphetamine on radial arm maze performance in the rat. Pharmacol. Biochem. Behav. 12: 595-602.

Fadda, F., Melis, F., and Stancampiano, R. 1996. Increased hippocampal acetylcholine release during a working memory task. Eur. J. Pharmacol. 307: R1-R2.

Fadda, F., Cocco, S., and Stancampiano, R. 2000. Hippocampal acetylcholine release correlates with spatial learning performance in freely moving rats. NeuroReport 11: 2265-2269.

Farr, S.A., Uezu, K., Flood, J.F., and Morley, J.E. 1999. Septo-hippocampal drug interactions in post-trial memory processing. Brain Res. 847: 221-230.

Farr, S.A., Flood, J.F., and Morley, J.E. 2000. The effect of cholinergic, GABAergic, serotonergic, and glutamatergic receptor modulation on posttrial memory processing in the hippocampus. Neurobiol. Learn. Mem. 73: 150-167.

Felix, R. and Levin, E.D. 1997. Nicotinic antagonist administration into the ventral hippocampus and spatial working memory in rats. Neuroscience 81: 1009-1017.

Freund, T.G. and Antal, M. 1988. GABA-containing neurons in the septum control inhibitory interneurons in the hippocampus. Nature 336: $170-173$.

Frick, K.M., Kim, J.J., and Baxter, M.G. 2004. Effects of complete immunotoxin lesions of the cholinergic basal forebrain on fear conditioning and spatial learning. Hippocampus (in press).

Frotscher, M. 1988. Cholinergic neurons in the rat hippocampus do not compensate for the loss of septohippocampal cholinergic fibers. Neurosci. Lett. 87: 18-22.

Frotscher, M. and Leranth, C. 1985. Cholinergic innervation of the rat hippocampus as revealed by choline acetyltransferase immunocytochemistry: A combined light and electron microscopic study. J. Comp. Neurol. 239: 237-246.

Frotscher, M., Schlander, M., and Léránth, C. 1986. Cholinergic neurons in the hippocampus: A combined light- and electron-microscopic immunocytochemical study in the rat. Cell Tissue Res. 246: 293-301.

Galani, R., Lehmann, O., Bolmont, T., Aloy, E., Bertrand, F., Lazarus, C., Jeltsch, H., and Cassel, J.C. 2002. Selective immunolesions of $\mathrm{CH} 4$ cholinergic neurons do not disrupt spatial memory in rats. Physiol. Behav. 76: 75-90.

Gale, G.D., Anagnostaras, S.G., and Fanselow, M.S. 2001. Cholinergic modulation of Pavlovian fear conditioning: Effects of intrahippocampal scopolamine infusion. Hippocampus 11: 371376.

Galey, D., Destrade, C., and Jaffard, R. 1994. Relationships between septo-hippocampal cholinergic activation and the improvement of long-term retention produced by medial septal electrical stimulation in two inbred strains of mice. Behav. Brain Res. 60: 183-189.

Gallagher, M., Bizon, J.L., Hoyt, E.C., Helm, K.A., and Lund, P.K. 2003. Effects of aging on the hippocampal formation in a naturally occurring animal model of mild cognitive impairment. Exp. Gerontol. 38: $71-77$.

Gandhi, C.C., Kelly, R.M., Wiley, R.G., and Walsh, T.J. 2000. Impaired acquisition of a Morris water maze task following selective destruction of cerebellar purkinje cells with OX7-saporin. Behav. Brain Res. 109: 37-47.

Gao, B., Hornung, J.P., and Fritschy, J.M. 1995. Identification of distinct GABAA-receptor subtypes in cholinergic and parvalbumin-positive neurons of the rat and marmoset medial septum-diagonal band complex. Neuroscience 65: 101-117.

Gibbs, R.B. 2002. Basal forebrain cholinergic neurons are necessary for estrogen to enhance acquisition of a delayed matching-to-position T-maze task. Horm. Behav. 42: 245-257.

Givens, B. and Olton, D.S. 1990. Cholinergic and GABAergic modulation of medial septal area: Effect on working memory. Behav. Neurosci. 104: 849-855.

-1995. Bidirectional modulation of scopolamine-induced working memory impairments by muscarinic activation of the medial septal area. Neurobiol. Learn. Mem. 63: 269-276.

Gorman, L.K., Pang, K., Frick, K.M., Givens, B., and Olton, D.S. 1994. Acetylcholine release in the hippocampus: Effects of cholinergic and GABAergic compounds in the medial septal area. Neurosci. Lett. 166: 199-202.

Hagan, J.J., Salamone, J.D., Simpson, J., Iversen, S.D., and Morris, R.G.M. 1988. Place navigation in rats is impaired by lesions of medial septum and diagonal band but not nucleus basalis magnocellularis. Behav. Brain Res. 27: 9-20.

Han, J.-S., Gallagher, M., and Holland, P.C. 1995. Hippocampal lesions disrupt decrements but not increments in conditioned stimulus processing. J. Neurosci. 15: 7323-7329.

Hasselmo, M.E. and Fehlau, B.P. 2001. Differences in time course of ACh and GABA modulation of excitatory synaptic potentials in slices of rat hippocampus. J. Neurophysiol. 86: 1792-1802.

Heckers, S., Ohtake, T., Wiley, R.G., Lappi, D.A., Geula, C., and Mesulam, M.-M. 1994. Complete and selective cholinergic denervation of rat neocortex and hippocampus but not amygdala by an immunotoxin against the p75 NGF receptor. J. Neurosci. 14: $1271-1289$.

Henderson, Z. 1995. Expression of GABAA receptor subunit messenger RNA in noncholinergic neurons of the rat basal forebrain. Neuroscience 65: 1077-1086.

Hepler, D.J., Olton, D.S., Wenk, G.L., and Coyle, J.T. 1985. Lesions in nucleus basalis magnocellularis and medial septal area of rats produce qualitatively similar memory impairments. J. Neurosci. 5: $866-873$

Hersi, A.I., Rowe, W., Gaudreau, P., and Quirion, R. 1995. Dopamine $D_{1}$ receptor ligands modulate cognitive performance and hippocampal acetylcholine release in memory-impaired aged rats. Neuroscience 69: 1067-1074.

Herzog, C.D., Gandhi, C., Bhattacharya, P., and Walsh, T.J. 2000. Effects of intraseptal zolpidem and chlordiazepoxide on spatial working memory and high-affinity choline uptake in the hippocampus. Neurobiol. Learn. Mem. 73: 168-179.

Hiramatsu, M., Mori, H., Murasawa, H., and Kameyama, T. 1996. Improvement by dynorphin $\mathrm{A}(1-13)$ of galanin-induced impairment of memory accompanied by blockade of reductions in acetylcholine release in rats. Br. J. Pharmacol. 118: 255-260.

Hironaka, N., Tanaka, K., Izaki, Y., Hori, K., and Nomura, M. 2001. Memory-related acetylcholine efflux from rat prefrontal cortex and hipppocampus: A microdialysis study. Brain Res. 901: 143-150.

Hodges, H., Allen, Y., Sinden, J., Lantos, P.L., and Gray, J.A. 1991. Effects of cholinergic-rich neural grafts on radial maze performance of rats after excitotoxic lesions of the forebrain cholinergic projection system-II. Cholinergic drugs as probes to investigate lesion-induced and transplant-induced functional recovery. Neuroscience 45: 609-623.

Howard III, M.A., Gross, A., Grady, M.S., Langer, R.S., Mathiowitz, E., Winn, H.R., and Mayberg, M.R. 1989. Intracerebral drug delivery in rats with lesion-induced memory deficits. J. Neurosurg. 71: 105-112.

Ikegami, S. 1994. Behavioral impairment in radial-arm maze learning and acetylcholine content of the hippocampus and cerebral cortex in aged mice. Behav. Brain Res. 65: 103-111.

Ikonen, S., McMahan, R., Gallagher, M., Eichenbaum, H., and Tanila, H. 2002. Cholinergic system regulation of spatial representation by the hippocampus. Hippocampus 12: 386-397.

Ipekoglu, S.Z., Buyukuysal, L., Ulus, I.H., and Korfali, E. 2000. Effects of fetal septal grafts on memory and learning performance with hippocampal acetylcholine and choline metabolism in fimbria transected rats. J. Neural Trans. 107: 191-202.

Izquierdo, I., da Cunha, C., Rosat, R., Jerusalinsky, D., Ferreira, M.B., and Medina, J.H. 1992. Neurotransmitter receptors involved in post-training memory processing by the amygdala, medial septum, and hippocampus of the rat. Behav. Neural Biol. 58: 16-26.

Janis, L.S., Glasier, M.M., Fulop, Z., and Stein, D.G. 1998. Intraseptal injections of 192 IgG-saporin produce deficits for strategy selection in spatial-memory tasks. Behav. Brain Res. 90: 23-34.

Janisiewicz, A.M. and Baxter, M.G. 2003. Transfer effects and conditional learning in rats with selective lesions of medial septal/diagonal band cholinergic neurons. Behav. Neurosci. 117: 1342-1352.

Janisiewicz, A.M., Jackson III, O., Firoz, E.F., and Baxter, M.G. 2004. Environment-spatial conditional learning in rats with selective lesions of medial septal cholinergic neurons. Hippocampus (in press).

Johnson, D.A., Zambon, N.J., and Gibbs, R.B. 2002. Selective lesion of cholinergic neurons in the medial septum by 192 IgG-saporin impairs learning in a delayed matching to position T-maze paradigm. Brain Res. 943: 132-141.

Köhler, C., Chan-Palay, V., and Wu, J.-Y. 1984. Septal neurons containing glutamic acid decarboxylase immunoreactivity project to the hippocampal region in the rat brain. Anat. Embryol. 169: 41-44.

Kelsey, J.E. and Landry, B.A. 1988. Medial septal lesions disrupt spatial mapping ability in rats. Behav. Neurosci. 102: 289-293.

Kelsey, J.E. and Vargas, H. 1993. Medial septal lesions disrupt spatial, but not nonspatial, working memory in rats. Behav. Neurosci. 107: $565-574$.

Kilgard, M.P. and Merzenich, M.M. 1998. Cortical map reorganization enabled by nucleus basalis activity. Science 279: 1714-1718.

Kim, J.S. and Levin, E.D. 1996. Nicotinic, muscarinic and dopaminergic actions in the ventral hippocampus and the nucleus accumbens: Effects on spatial working memory in rats. Brain Res. 725: 231-240.

Kirby, B.P. and Rawlins, J.N. 2003. The role of the septo-hippocampal 
cholinergic projection in T-maze rewarded alternation. Behav. Brain Res. 143: 41-48.

Kopf, S.R., Buchholzer, M.L., Hilgert, M., Loffelholz, K., and Klein, J. 2001. Glucose plus choline improve passive avoidance behaviour and increase hippocampal acetylcholine release in mice. Neuroscience 103: $365-371$.

Leanza, G., Nilsson, O.G., Wiley, R.G., and Björklund, A. 1995. Selective lesioning of the basal forebrain cholinergic system by intraventricular 192 IgG-saporin: Behavioural, biochemical and stereological studies in the rat. Eur. J. Neurosci. 7: 329-343.

Leanza, G., Muir, J., Nilsson, O.G., Wiley, R.G., Dunnett, S.B., and Bjorklund, A. 1996. Selective immunolesioning of the basal forebrain cholinergic system disrupts short-term memory in rats. Eur. J. Neurosci. 8: 1535-1544.

LeBlanc, C.J., Deacon, T.W., Whatley, B.R., Dinsmore, J., Lin, L., and Isacson, O. 1999. Morris water maze analysis of 192-IgG-saporin-lesioned rats and porcine cholinergic transplants to the hippocampus. Cell Transplant. 8: 131-142.

Lebrun, C., Durkin, T.P., Marighetto, A., and Jaffard, R. 1990. A comparison of the working memory performances of young and aged mice combined with parallel measures of testing and drug-induced activations of septo-hippocampal and nbm-cortical cholinergic neurones. Neurobiol. Aging 11: 515-521.

Lehmann, O., Jeltsch, H., Lehnardt, O., Pain, L., Lazarus, C., and Cassel, J.-C. 2000. Combined lesions of cholinergic and serotonergic neurons in the rat brain using 192 IgG-saporin and 5,7-dihydroxytryptamine: Neurochemical and behavioural characterization. Eur. J. Neurosci. 12: 67-79.

Lehmann, O., Bertrand, F., Jeltsch, H., Morer, M., Lazarus, C., Will, B., and Cassel, J.-C. 2002a. 5,7-DHT-induced hippocampal 5-HT depletion attenuates behavioural deficits produced by 192 IgG-saporin lesions of septal cholinergic neurons in the rat. Eur. J. Neurosci. 15: 1991-2006.

Lehmann, O., Jeltsch, H., Lazarus, C., Tritschler, L., Bertrand, F., and Cassel, J.-C. 2002b. Combined 192 IgG-saporin and 5,7-dihydroxytryptamine lesions in the male rat brain: A neurochemical and behavioral study. Pharmacol. Biochem. Behav. 72: 899-912.

Lehmann, O., Grottick, A.J., Cassel, J.-C., and Higgins, G.A. 2003. A double dissociation between serial reaction time and radial maze performance in rats subjected to 192 IgG-saporin lesions of the nucleus basalis and/or the septal region. Eur. J. Neurosci. 18: $651-666$

Levey, A.I., Edmunds, S.M., Hersch, S.M., Wiley, R.G., and Heilman, C.J. 1995. Light and electron microscopic study of m2 muscarinic acetylcholine receptor in the basal forebrain of the rat. J. Comp. Neurol. 351: 339-356.

Levin, E.D., Christopher, N.C., Briggs, S.J., and Rose, J.E. 1993. Chronic nicotine reverses working memory deficits caused by lesions of the fimbria or medial basalocortical projection. Cog. Brain Res. 1: $137-143$.

Levin, E.D., Bradley, A., Addy, N., and Sigurani, N. 2002. Hippocampal $\alpha 7$ and $\alpha 4 \beta 2$ nicotinic receptors and working memory. Neuroscience 109: 757-765.

Levy, A., Kong, R.M., Stillman, M.J., Shukitt-Hale, B., Kadar, T., Rauch, T.M., and Lieberman, H.R. 1991. Nimodipine improves spatial working memory and elevates hippocampal acetylcholine in young rats. Pharmacol. Biochem. Behav. 39: 781-786.

Lewis, P.R., Shute, C.C.D., and Silver, A. 1967. Confirmation from choline acetylase analyses of a massive cholinergic innervation to the rat hippocampus. J. Physiol. 191: 215-224.

Li, Y.J., Simon, J.R., and Low, W.C. 1992. Intrahippocampal grafts of cholinergic-rich striatal tissue ameliorate spatial memory deficits in rats with fornix lesions. Brain Res. Bull. 29: 147-155.

Lippa, A.S., Pelham, R.W., Beer, B., Critchett, D.J., Dean III, R.L., and Bartus, R.T. 1980. Brain cholinergic dysfunction and memory in aged rats. Neurobiol. Aging 1: 13-19.

Lippa, A.S., Loullis, C.C., Rotrosen, J., Cordasco, D.M., Critchett, D.J., and Joseph, J.A. 1985. Conformational changes in muscarinic receptors may produce diminished cholinergic neurotransmission and memory deficits in aged rats. Neurobiol. Aging 6: 317-323.

Low, W.C., Lewis, P.R., Bunch, S.T., Dunnett, S.B., Thomas, S.R., Iversen, S.D., Bjorklund, A., and Stenevi, U. 1982. Function recovery following neural transplantation of embryonic septal nuclei in adult rats with septohippocampal lesions. Nature 300: 260-262.

Maaswinkel, H. and Whishaw, I.Q. 1999. Homing with locale, taxon, and dead reckoning strategies by foraging rats: Sensory hierarchy in spatial navigation. Behav. Brain Res. 99: 143-152.

Maaswinkel, H., Jarrard, L.E., and Whishaw, I.Q. 1999. Hippocampectomized rats are impaired in homing by path integration. Hippocampus 9: 553-561.

Maho, C., Dutrieux, G., and Ammassari-Teule, M. 1988. Parallel modifications of spatial performances, exploration patterns, and hippocampal \&theta; rhythms in fornix-damaged rats: Reversal by oxotremorine. Behav. Neurosci. 102: 601-604.

Mahut, H. 1972. A selective spatial deficit in monkeys after transection of the fornix. Neuropsychologia 10: $65-74$.

Marighetto, A., Durkin, T., Toumane, A., Lebrun, C., and Jaffard, R. 1989. Septal $\alpha$-noradrenergic antagonism in vivo blocks the testing-induced activation of septo-hippocampal cholinergic neurones and produces a concomitant deficit in working memory performance of mice. Pharmacol. Biochem. Behav. 34: 553-558.

Marighetto, A., Micheau, J., and Jaffard, R. 1993. Relationships between testing-induced alterations of hippocampal cholinerigic activity and memory performance on two spatial tasks in mice. Behav. Brain Res. 56: $133-144$.

. 1994. Effects of intraseptally injected glutamatergic drugs on hippocampal sodium-dependent high-affinity choline uptake in "naive" and "trained" mice. Pharmacol. Biochem. Behav. 49: 689-699.

Markowska, A.L., Olton, D.S., Murray, E.A., and Gaffan, D. 1989. A comparative analysis of the role of fornix and cingulate cortex in memory: Rats. Exp. Brain Res. 74: 187-201.

Markowska, A.L., Olton, D.S., and Givens, B. 1995. Cholinergic manipulations in the medial septal area: Age-related effects on working memory and hippocampal electrophysiology. J. Neurosci. 15: $2063-2073$

Martin, G.M., Harley, C.W., Smith, A.R., Hoyles, E.S., and Hynes, C.A. 1997. Spatial disorientation blocks reliable goal location on a plus maze but does not prevent goal location in the Morris maze. J. Exp. Psychol. Anim. Behav. Process. 23: 183-193.

Martin, S.J., Grimwood, P.D., and Morris, R.G. 2000. Synaptic plasticity and memory: An evaluation of the hypothesis. Ann. Rev. Neurosci. 23: $649-711$.

Mash, D.C. and Potter, L.T. 1986. Autoradiographic localization of M1 and M2 muscarine receptors in the rat brain. Neuroscience 19: $551-564$.

McDonald, R.J. and White, N.M. 1993. A triple dissociation of memory systems: Hippocampus, amygdala, and dorsal striatum. Behav. Neurosci. 107: 3-22.

McGaugh, J.L., Ferry, B., Vazdarjanova, A., and Roozendaal, B. 2000. Amygdala: Role in modulation of memory storage. In The amygdala: A functional analysis (ed. J.P. Aggleton), pp. 391-423. Oxford University Press, Oxford, UK.

McGaughy, J. and Sarter, M. 1998. Sustained attention performance in rats with intracortical infusions of 192 IgG-saporin-induced cortical cholinergic deafferentation: Effects of physostigmine and FG 7142. Behav. Neurosci. 112: 1519-1525.

McGaughy, J., Kaiser, T., and Sarter, M. 1996. Behavioral vigilance following infusions of $192 \mathrm{IgG}$-saporin into the basal forebrain: Selectivity of the behavioral impairment and relation to cortical AChE-positive fiber density. Behav. Neurosci. 110: 247-265.

McGaughy, J., Dalley, J.W., Morrison, C.H., Everitt, B.J., and Robbins, T.W. 2002. Selective behavioral and neurochemical effects of cholinergic lesions produced by intrabasalis infusions of 192 IgG-saporin on attentional performance in a five-choice serial reaction time task. J. Neurosci. 22: 1905-1913.

McIntyre, C.K., Pal, S.N., Marriott, L.K., and Gold, P.E. 2002. Competition between memory systems: Acetylcholine release in the hippocampus correlates negatively with good performance on an amygdala-dependent task. J. Neurosci. 22: 1171-1176.

McIntyre, C.K., Marriott, L.K., and Gold, P.E. 2003. Patterns of brain acetylcholine release predict individual differences in preferred learning strategies in rats. Neurobiol. Learn. Mem. 79: 177-183.

McMahan, R.W., Sobel, T.J., and Baxter, M.G. 1997. Selective immunolesions of hippocampal cholinergic input fail to impair spatial working memory. Hippocampus 7: 130-136.

Melis, F., Stancampiano, R., Imperato, A., Carta, G., and Fadda, F. 1996. Chronic ethanol consumption in rats: Correlation between performance and hippocampal acetylcholine release in vivo. Neuroscience 74: 155-159.

Mesulam, M.-M., Mufson, E.J., Wainer, B.H., and Levey, A.I. 1983. Central cholinergic pathways in the rat: An overview based on an alternative nomenclature (Ch1-Ch6). Neuroscience 10: 1185-1201.

Mishima, K., Egashira, N., Matsumoto, Y., Iwasaki, K., and Fugiwara, M. 2002. Involvement of reduced acetylcholine release in Delta ${ }^{9}$-tetrahydrocannabinol-induced impairment of spatial memory in the 8-arm radial maze. Life Sci. 72: 397-407.

Mitchell, S.J., Rawlins, J.N.P., Steward, O., and Olton, D.S. 1982. Medial septal area lesions disrupt $\mathrm{q}$ rhythm and cholinergic staining in medial entorhinal cortex and produce impaired radial arm maze behavior in rats. J. Neurosci. 2: 292-302.

Molyneaux, B.J. and Hasselmo, M.E. 2002. GABA(B) presynaptic inhibition has an in vivo time constant sufficiently rapid to allow modulation at $\theta$ frequency. J. Neurophysiol. 87: 1196-1205. 
Moor, E., DeBoer, P., and Westerink, B.H. 1998a. GABA receptors and benzodiazepine binding sites modulate hippocampal acetylcholine release in vivo. Eur. J. Pharmacol. 359: 119-126.

Moor, E., Schirm, E., Jasco, J., and Westerink, B.H. 1998b. Involvement of medial septal glutamate and GABAA receptors in behavior-induced acetylcholine release in the hippocampus: A dual probe microdialysis study. Brain Res. 789: 1-8.

Moser, E., Moser, M.-B., and Andersen, P. 1993. Spatial learning impairment parallels the magnitude of dorsal hippocampal lesions, but is hardly present following ventral lesions. J. Neurosci. 13: 3916-3925.

Muir, J.L. 1996. Attention and stimulus processing in the rat. Cog. Brain Res. 3: 215-225.

Myers, C.E., Kluger, A., Golomb, J., Ferris, S., de Leon, M.J., Schnirman, G., and Gluck, M.A. 2002. Hippocampal atrophy disrupts transfer generalization in nondemented elderly. J. Geriatr. Psychiatry Neurol. 15: 82-90.

Nail-Boucherie, K., Dourmap, N., Jaffard, R., and Costentin, J. 2000. Contextual fear conditioning is associated with an increase of acetylcholine release in the hippocampus of rat. Cog. Brain Res. 9: 193-197.

Nakamura, A., Suzuki, Y., Umegaki, H., Ikari, H., Tajima, T., Endo, H., and Iguchi, A. 2001. Dietary restriction of choline reduces hippocampal acetylcholine release in rats: In vivo microdialysis study. Brain Res. Bull. 56: 593-597.

Nava, F., Carta, G., Battasi, A.M., and Gessa, G.L. 2000. $D_{2}$ dopamine receptors enable Delta ${ }^{9}$-tetrahydocannabinol induced memory impairment and reduction of hippocampal extracellular acetylcholine concentration. Br. J. Pharmacol. 130: 1201-1210.

Nava, F., Carta, G., Colombo, G., and Gessa, G.L. 2001. Effects of chronic Delta ${ }^{9}$-tetrahydrocannabinol treatment on hippocampal extracellular acetylcholine concentration and alternation performance in the T-maze. Neuropharmacol. 41: 392-399.

Nilsson, O.G., Shapiro, M.L., Gage, F.H., Olton, D.S., and Bjorklund, A. 1987. Spatial learning and memory following fimbria-fornix transection and grafting of fetal septal neurons to the hippocampus. Exp. Brain Res. 67: 195-215.

Nilsson, O.G., Leanza, G., Rosenblad, C., Lappi, D.A., Wiley, R.G., and Björklund, A. 1992. Spatial learning impairments in rats with selective immunolesion of the forebrain cholinergic system. NeuroReport 3: 1005-1008.

Ohno, M., Yamamoto, T., and Watanabe, S. 1993. Blockade of hippocampal nicotinic receptors impairs working memory but not reference memory in rats. Pharmacol. Biochem. Behav. 45: 89-93.

Ohno, M., Kobayashi, M., Kishi, A., and Watanabe, S. 1997a. Working memory failure by combined blockade of muscarinic and $\beta$-adrenergic transmission in the rat hippocampus. NeuroReport 8: $1571-1575$.

Ohno, M., Yoshimatsu, A., Kobayashi, M., and Watanabe, S. 1997b. Noradrenergic DSP-4 lesions aggravate impairment of working memory produced by hippocampal muscarinic blockade in rats. Pharmacol. Biochem. Behav. 57: 257-261.

Olariu, A., Tran, M.H., Yamada, K., Mizuno, M., Hefco, V., and Nabeshima, T. 2001. Memory deficits and increased emotionality induced by b-amyloid(25-35) are correlated with the reduced acetylcholine release and altered phorbol dibutyrate binding in the hippocampus. J. Neural Transm. 108: 1065-1079.

Olton, D.S., Walker, J.A., and Gage, F.H. 1978. Hippocampal connections and spatial discrimination. Brain Res. 139: 295-308.

Orsetti, M., Casamenti, F., and Pepeu, G. 1996. Enhanced acetylcholine release in hippocampus and cortex during acquisition of an operant behavior. Brain Res. 724: 89-96.

Packard, M.G., Cahill, L., and McGaugh, J.L. 1994. Amygdala modulation of hippocampal-dependent and caudate nucleus-dependent memory processes. Proc. Natl. Acad. Sci. 91: $8477-8481$.

Pallage, V., Toniolo, G., Will, B., and Hefti, F. 1986. Long-term effects of nerve growth factor and neural transplants on behavior of rats with medial septal lesions. Brain Res. 386: 197-208.

Pang, K.C., Nocera, R., Secor, A.J., and Yoder, R.M. 2001. GABAergic septohippocampal neurons are not necessary for spatial memory. Hippocampus 11: 814-827.

Pang, K.C.H. and Nocera, R. 1999. Interactions between 192-IgG saporin and intraseptal cholinergic and GABAergic drugs: Role of cholinergic medial septal neurons in spatial working memory. Behav. Neurosci. 113: $265-275$.

Parent, M.B., Laurey, P.T., Wilkniss, S., and Gold, P.E. 1997. Intraseptal infusions of muscimol impair spontaneous alternation performance: Infusions of glucose into the hippocampus, but not the medial septum, reverse the deficit. Neurobiol. Learn. Mem. 68: 75-85.

Park, G.A., Pappas, B.A., Maurtha, S.M., and Ally, A. 1992. Enriched environment primes forebrain choline acetyltransferase activity to respond to learning experience. Neurosci. Lett. 143: 259-262.

Perry, D.C. and Kellar, K.J. 1995. [3H]epibatidine labels nicotinic receptors in rat brain: An autoradiographic study. J. Pharm. Exp. Ther. 275: 1030-1034.

Perry, T., Hodges, H., and Gray, J.A. 2001. Behavioural, histological and immunocytochemical consequences following 192 IgG-saporin immunolesions of the basal forebrain cholinergic system. Brain Res. Bull. 54: $29-48$.

Peterson, G.M. and Shurlow, C.L. 1992. Morphological evidence for a substance $\mathrm{P}$ projection from medial septum to hippocampus. Peptides 13: $509-517$.

Pizzo, D.P., Thal, L.J., and Winkler, J. 2002. Mnemonic deficits in animals depend upon the degree of cholinergic deficit and task complexity. Exp. Neurol. 177: 292-305.

Potter, P.E., Gaughan, C., and Assouline, Y. 1999. Lesion of septal-hippocampal neurons with 192 IgG-saporin alters function of M1 muscarinic receptors. Neuropharmacol. 38: 579-586.

Power, J.M. and Sah, P. 2002. Nuclear calcium signaling evoked by cholinergic stimulation in hippocampal CA1 pyramidal neurons. $J$. Neurosci. 22: 3454-3462.

Ragozzino, M.E. and Gold, P.E. 1995. Glucose injections into the medial septum reverse the effects of intraseptal morphine infusions on hippocampal acetylcholine output and memory. Neuroscience 68: $981-988$.

Ragozzino, M.E., Parker, M.E., and Gold, P.E. 1992. Spontaneous alternation and inhibitory avoidance impairments with morphine injections into the medial septum. Brain Res. 597: 241-249.

Ragozzino, M.E., Unick, K.E., and Gold, P.E. 1996. Hippocampal acetylcholine release during memory testing in rats: Augmentation by glucose. Proc. Natl. Acad. Sci. 93: 4693-4698.

Ragozzino, M.E., Pal, S.N., Unick, K., Stefani, M.R., and Gold, P.E. 1998. Modulation of hippocampal acetylcholine release and spontaneous alternation scores by intrahippocampal glucose injections. $J$. Neurosci. 18: 1595-1601.

Rawlins, J.N. and Olton, D.S. 1982. The septo-hippocampal system and cognitive mapping. Behav. Brain Res. 5: 331-358.

Reber, P.J., Knowlton, B.J., and Squire, L.R. 1996. Dissociable properties of memory systems: Differences in the flexibility of declarative and nondeclarative knowledge. Behav. Neurosci. 110: 861-871.

Richmond, M.A., Nichols, B.P., Deacon, R.M., and Rawlins, J.N. 1997. Effects of scopolamine and hippocampal lesions on negative patterning discrimination performance in rats. Behav. Neurosci. 111: $1217-1227$.

Ridley, R.M., Thornley, H.D., Baker, H.F., and Fine, A. 1991. Cholinergic neural transplants into hippocampus restore learning ability in monkeys with fornix transections. Exp. Brain Res. 83: 533-538.

Ridley, R.M., Barefoot, H.C., Maclean, C.J., Pugh, P., and Baker, H.F. 1999. Different effects on learning ability after injection of the cholinergic immunotoxin ME20.4IgG-saporin into the diagonal band of Broca, basal nucleus of Meynert, or both in monkeys. Behav. Neurosci. 113: 303-315.

Roßner, S., Schliebs, R., Perez-Polo, J.R., Wiley, R.G., and Bigl, V. 1995. Differential changes in cholinergic markers from selected brain regions after specific immunolesion of the rat cholinergic basal forebrain. J. Neurosci. Res. 40: 31-43.

Rosenzweig, E.S. and Barnes, C.A. 2003. Impact of aging on hippocampal function: Plasticity, network dynamics, and cognition. Prog. Neurobiol. 69: 143-179.

Rouse, S.T. and Levey, A.I. 1996. Expression of m1-m4 muscarinic acetylcholine receptor immunoreactivity in septohippocampal neurons and other identified hippocampal afferents. J. Comp. Neurol. 375: 406-416.

Rye, D.B., Wainer, B.H., Mesulam, M.-M., Mufson, E.J., and Saper, C.B. 1984. Cortical projections arising from the basal forebrain: A study of cholinergic and noncholinergic components employing combined retrograde tracing and immunohistochemical localization of choline acetyltransferase. Neuroscience 13: 627-643.

Sarter, M. and McGaughy, J. 1998. Assessment of sustained and divided attention in rats: Aspects of validity [comment]. Psychopharmacol. 138: $260-262$.

Sarter, M., Bruno, J.P., and Himmelheber, A.M. 1997. Cortical acetylcholine and attention: Neuropharmacological and cognitive principles directing treatment strategies for cognitive disorders. In Pharmacological treatment of Alzheimer's disease: Molecular and neurobiological foundations (eds. J.D. Brioni and M.W. Decker), pp. 105-128. Wiley, New York.

Sarter, M., Bruno, J.P., and Turchi, J. 1999. Basal forebrain afferent projections modulating cortical acetylcholine, attention, and implications for neuropsychiatric disorders. Ann. NY Acad. Sci. 877: 368-382.

Sarter, M., Bruno, J.P., and Givens, B. 2003. Attentional functions of cortical cholinergic inputs: What does it mean for learning and 
memory? Neurobiol. Learn. Mem. 80: 245-256.

Sarter, M.F., Draut, A., Herzog, C.D., and Bruno, J.P. 2002. Effects of septohippocampal cholinergic deafferentation on attention and learning. Program No. 674.8. http://sfn.scholarone.com

Scali, C., Casamenti, F., Pazzagli, M., Bartolini, L., and Pepeu, G. 1994. Nerve growth factor increases extracellular acetylcholine levels in the parietal cortex and hippocampus of aged rats and restores object recognition. Neurosci. Lett. 170: 117-120.

Scali, C., Giovannini, M.G., Bartolini, L., Prosperi, C., Hinz, V., Schmidt, B., and Pepeu, G. 1997a. Effect of metrifonate on extracellular brain acetylcholine and object recognition in aged rats. Eur. J. Pharmacol. 325: 173-180.

Scali, C., Giovannini, M.G., Prosperi, C., Bartolini, L., and Pepeu, G. 1997b. Tacrine administration enhances extracellular acetylcholine in vivo and restores the cognitive impairment in aged rats. Pharmacol. Res. 36: 463-469.

Senut, M.C., Menetrey, D., and Lamour, Y. 1989. Cholinergic and peptidergic projections from the medial septum and the nucleus of the diagonal band of Broca to dorsal hippocampus, cingulate cortex, and olfactory bulb: A combined wheatgerm

agglutinin-apohorseradish peroxidase-gold immunohistochemical study. Neuroscience 30: 385-403.

Shen, J., Barnes, C.A., Wenk, G.L., and McNaughton, B.L. 1996 Differential effects of selective immunotoxic lesions of medial septal cholinergic cells on spatial working and reference memory. Behav. Neurosci. 110: 1181-1186.

Sherman, K.A., Kuster, J.E., Dean III, R.L., Bartus, R.T., and Friedman, E. 1981. Presynaptic cholinergic mechanisms in brain of aged rats with memory impairments. Neurobiol. Aging 2: 99-104.

Solomon, P.R., Solomon, S.D., Schaaf, E.V., and Perry, H.E. 1983. Altered activity in the hippocampus is more detrimental to classical conditioning than removing the structure. Science 220: 329-331.

Sorger, D., Kampfer, I., Schliebs, R., Rossner, S., Dannenberg, C., and Knapp, W.H. 1999. Iodo-QNB cortical binding and brain perfusion: Effects of a cholinergic basal forebrain lesion in the rat. Nucl. Med. Biol. 26: 9-16.

Sotty, F., Danik, M., Manseau, F., Laplante, F., Quirion, R., and Williams, S. 2003. Distinct electrophysiological properties of glutamatergic, cholinergic and GABAergic septohippocampal neurons: Novel implications for hippocampal rhythmicity. J. Physiol. 551.3: 927-943.

Stancampiano, R., Cocco, S., Cugusi, C., Sarais, L., and Fadda, F. 1999. Serotonin and acetylcholine release response in the rat hippocampus during a spatial memory task. Neuroscience 89: 1135-1143.

Stefani, M.R. and Gold, P.E. 2001. Intrahippocampal infusions of K-ATP channel modulators influence spontaneous alternation performance: Relationships to acetylcholine release in the hippocampus. $J$. Neurosci. 21: 609-614.

Stevens, R. 1981. Scopolamine impairs spatial maze performance in rats. Physiol. Behav. 27: 385-386.

Tarricone, B.J., Keim, S.R., Simon, J.R., and Low, W.C. 1991. Intrahippocampal transplants of septal cholinergic neurons: High-affinity choline uptake and spatial memory function. Brain Res. 548: $55-62$.

Tarricone, B.J., Simon, J.R., and Low, W.C. 1993. Intrahippocampal transplants of septal cholinergic neurons: Choline acetyltransferase activity, muscarinic receptor binding, and spatial memory formation. Brain Res. 632: 41-47.

Tarricone, B.J., Simon, J.R., Li, Y.J., and Low, W.C. 1996. Neural grafting of cholinergic neurons in the hippocampal formation. Behav. Brain Res. 74: 25-44.

Torres, E.M., Perry, T.A., Blokland, A., Wilkinson, L.S., Wiley, R.G., Lappi, D.A., and Dunnett, S.B. 1994. Behavioural, histochemical and biochemical consequences of selective immunolesions in discrete regions of the basal forebrain cholinergic system. Neuroscience 63: $95-122$.

Toth, K., Freund, T.F., and Miles, R. 1997. Disinhibition of rat hippocampal pyramidal cells by GABAergic afferents from the septum. J. Physiol. 500 (Pt 2): 463-474.

Toumane, A., Durkin, T., Marighetto, A., Galey, D., and Jaffard, R. 1988. Differential hippocampal and cortical cholinergic activation during the acquisition, retention, reversal and extinction of a spatial discrimination in an 8-arm radial maze by mice. Behav. Brain Res. 30: $225-234$.

Toumane, A., Durkin, T., Marighetto, A., and Jaffard, R. 1989. The durations of hippocampal and cortical cholinergic activation induced by spatial discrimination testing of mice in an eight-arm radial maze decrease as a function of acquisition. Behav. Neural Biol. 52: $279-284$
Turchi, J. and Sarter, M. 2000. Cortical cholinergic inputs mediate processing capacity: Effects of 192 IgG-saporin-induced lesions on olfactory span performance. Eur. J. Neurosci. 12: 45054514.

Vale-Martínez, A., Baxter, M.G., and Eichenbaum, H. 2002. Selective lesions of basal forebrain cholinergic neurons produce anterograde and retrograde deficits in a social transmission of food preference task in rats. Eur. J. Neurosci. 16: 983-998.

Van der Zee, E.A. and Luiten, P.G.M. 1994. Cholinergic and GABAergic neurons in the rat medial septum express muscarinic cholinergic receptors. Brain Res. 652: 263-272.

Vuckovich, J.A., Semel, M.E., and Baxter, M.G. 2004. Extensive lesions of cholinergic basal forebrain neurons do not impair spatial working memory. Learn Mem. (this issue).

Waite, J.J. and Chen, A.D. 2001. Differential changes in rat cholinergic parameters subsequent to immunotoxic lesion of the basal forebrain nuclei. Brain Res. 918: 113-120.

Waite, J.J., Chen, A.D., Wardlow, M.L., Wiley, R.G., Lappi, D.A., and Thal, L.J. 1995. 192 immunoglobulin G-saporin produces graded behavioral and biochemical changes accompanying the loss of cholinergic neurons of the basal forebrain and cerebellar Purkinje cells. Neuroscience 65: 463-476.

Waite, J.J., Wardlow, M.L., and Power, A.E. 1999. Deficit in selective and divided attention associated with cholinergic basal forebrain immunotoxic lesion produced by 192-saporin; motoric/sensory deficit associated with Purkinje cell immunotoxic lesion produced by OX7-saporin. Neurobiol. Learn. Mem. 71: 325-352.

Wallenstein, G.V. and Hasselmo, M.E. 1997. GABAergic modulation of hippocampal population activity: Sequence learning, place field development, and the phase precession effect. J. Neurophysiol. 78: $393-408$.

Wallenstein, G.V. and Vago, D.R. 2001. Intrahippocampal scopolamine impairs both acquisition and consolidation of contextual fear conditioning. Neurobiol. Learn. Mem. 75: 245-252.

Walsh, T.J., Kelly, R.M., Dougherty, K.D., Stackman, R.W., Wiley, R.G., and Kutscher, C.L. 1995. Behavioral and neurobiological alterations induced by the immunotoxin 192-IgG-saporin: Cholinergic and noncholinergic effects following i.c.v. injection. Brain Res. 702: $233-245$.

Walsh, T.J., Herzog, C.D., Gandhi, C., Stackman, R.W., and Wiley, R.G. 1996. Injection of 192 IgG-saporin into the medial septum produces cholinergic hypofunction and dose-dependent working memory deficits. Brain Res. 726: 69-79.

Wan, R.Q., Pang, K., and Olton, D.S. 1997. Nonhippocampal muscarinic receptors are required for nonspatial working memory. Pharmacol. Biochem. Behav. 58: 361-367.

Wenk, G., Hepler, D., and Olton, D. 1984. Behavior alters the uptake of $\left[{ }^{3} \mathrm{H}\right]$ choline into acetylcholinergic neurons of the nucleus basalis magnocellularis and medial septal area. Behav. Brain Res. 13: $129-138$.

Westlind, A., Grynfarb, M., Hedlund, B., Bartfai, T., and Fuxe, K. 1981. Muscarinic supersensitivity induced by septal lesion or chronic atropine treatment. Brain Res. 225: 131-141.

Wets, K.M., Sinden, J., Hodges, H., Allen, Y., and Marchbanks, R.M. 1991. Specific brain protein changes correlated with behaviorally effective brain transplants. J. Neurochem. 57: 1661-1670.

Whishaw, I.Q., Cassel, J.-C., and Jarrard, L.E. 1995. Rats with fimbria-fornix lesions display a place response in a swimming pool: A dissociation between getting there and knowing where. J. Neurosci. 15: $5779-5788$.

Woolf, N.J. 1996. The critical role of cholinergic basal forebrain neurons in morphological change and memory encoding: A hypothesis. Neurobiol. Learn. Mem. 66: 258-266.

Wrenn, C.C. and Wiley, R.G. 2001. Lack of effect of moderate Purkinje cell loss on working memory. Neuroscience 107: 433-445.

Wrenn, C.C., Lappi, D.A., and Wiley, R.G. 1999. Threshold relationship between lesion extent of the cholinergic basal forebrain in the rat and working memory impairment in the radial maze. Brain Res. 847: 284-298.

Wu, M., Shanabrough, M., Leranth, C., and Alreja, M. 2000. Cholinergic excitation of septohippocampal GABA but not cholinergic neurons: Implications for learning and memory. J. Neurosci. 20: 39003908.

Yamamuro, Y., Hori, K., Tanaka, K., Iwano, H., and Nomura, M. 1995. Septo-hippocampal cholinergic system under the discrimination learning task in the rat: A microdialysis study with the dual-probe approach. Brain Res. 684: 1-7. 


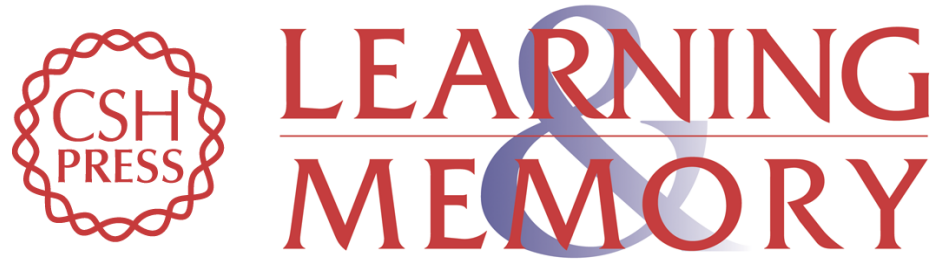

\title{
Septohippocampal Acetylcholine: Involved in but not Necessary for Learning and Memory?
}

\author{
Marise B. Parent and Mark G. Baxter
}

Learn. Mem. 2004, 11:

Access the most recent version at doi:10.1101//m.69104

References This article cites 233 articles, 29 of which can be accessed free at: http://learnmem.cshlp.org/content/11/1/9.full.html\#ref-list-1

License

Email Alerting

Receive free email alerts when new articles cite this article - sign up in the box at the Service top right corner of the article or click here. 